\title{
Children's Sleep May Depend on Maternal Sleep Duration During Pregnancy: A Retrospective Study
}

This article was published in the following Dove Press journal:

Nature and Science of Sleep

\begin{abstract}
Jiajun Lyu ${ }^{1, *}$
Xiuxia $\mathrm{Ye}^{2, *}$

Yiting Chen'

Yuanqing $\mathrm{Xia}^{\prime}$

Jianzhen $\mathrm{Zhu}^{3}$

Shilu Tong (ID) ${ }^{1,2,4}$

Yong Yin (D) ${ }^{2}$

Jiajie $Q u^{5}$

Shenghui Li (D) ${ }^{1,6}$

'School of Public Health, Shanghai Jiao Tong University School of Medicine, Shanghai, People's Republic of China; ${ }^{2}$ Shanghai Children's Medical Center, Shanghai Jiao

Tong University School of Medicine, Shanghai, People's Republic of China;

${ }^{3}$ School of International and Public Affairs, Shanghai Jiao Tong University, Shanghai, People's Republic of China; ${ }^{4}$ School of Public Health and Social Work, Queensland University of Technology, Brisbane, QLD, Australia; ${ }^{5}$ Shanghai Municipal Education Commission, Shanghai, People's Republic of China; 'MOE-Shanghai Key Laboratory of Children's Environmental Health, Shanghai Jiao Tong University School of Medicine, Shanghai, People's Republic of China
\end{abstract}

*These authors contributed equally to this work

Correspondence: Shenghui Li School of Public Health, Shanghai Jiao

Tong University School of Medicine, 227

South Chongqing Road, Huangpu District,

Shanghai 200025, People's Republic of

China

Tel +86-2I-63846590

Email Ish9907@I63.com

Jiajie Qu

Shanghai Municipal Education

Commission, 100 Dagu Road, Huangpu

District, Shanghai 200003, People's

Republic of China

Tel +86-2I-23I I I I I I

Email qujiajie@vip.163.com
Background: Animal studies suggested that maternal sleep during pregnancy was associated with sleep pattern in offspring; however, it has not been clear in human populations. Aim: Our study discusses the relationships of maternal sleep duration with sleep characteristics in their offspring through an epidemiological study.

Methods: A retrospective cross-sectional study including 6236 mother-child dyads was conducted in 31 preschools in May 2019, in Shanghai, China. Information regarding maternal sleep duration in three trimesters of pregnancy was collected retrospectively. Children's current sleep characteristics were evaluated through the Children's Sleep Habits Questionnaire (CSHQ). Linear regressions and logistic regression models were applied to estimate $\beta$ and adjusted odds ratios with $95 \%$ confidence intervals $(95 \% \mathrm{CI})$.

Results: Maternal sleep duration was positively associated with childhood sleep duration, which was shown in the first $(\beta=0.113)$, second $(\beta=0.131)$, and third trimesters $(\beta=0.088)$. Meanwhile, insufficient maternal sleep duration could increase the risk of children's short sleep duration (first trimester: $\mathrm{AOR}=1.25$; second trimester: $\mathrm{AOR}=1.33$; third trimester: $\mathrm{AOR}=1.33$ ). Maternal sleep duration was also associated with childhood CSHQ score: $\beta=$ $-0.308,-0.392$, and -0.300 for the first, second, and third trimesters, respectively. Similarly, insufficient maternal sleep duration could predict childhood sleep disturbance as $A O R=1.28$ in the second trimester and $\mathrm{AOR}=1.26$ in the third trimester.

Conclusion: Our findings established a relationship between maternal sleep during pregnancy and their children's sleep pattern through a population-based epidemiology study. Poor childhood sleep was found when their mother experienced less sleep duration during pregnancy, especially in the second and third trimesters.

Keywords: Children's Sleep Habit Questionnaire, pregnant women, preschooler, sleep duration

\section{Introduction}

It is reported that sleep problems have influenced almost the half of all children around the world. ${ }^{1}$ Sufficient high-quality sleep duration has benefits for children's health, growth, and development. ${ }^{2-5}$ It has been confirmed by accumulating studies that short sleep duration and sleep disturbance have negative impacts upon a range of aspects including metabolic balance, neurobehavioral function, and mental health. ${ }^{2-7}$

To date, a large number of factors have been reported affect children's sleep. However, almost all studies focused on children's own environmental exposure, lifestyle factors, and health condition, such as family members' interaction, sleep environment, physical activity, obesity, etc. ${ }^{8-12}$ Data from the ALSPAC cohort in the UK indicated that maternal mood disturbance in pregnancy has persisting 
effects on sleep problems in their children. ${ }^{13}$ A very recent study in Finland also suggested that maternal depressive symptoms during pregnancy are associated with an increased risk of children's sleep deficiency and sleep disorders. ${ }^{14}$ It seemed that there should be a link between maternal condition during pregnancy and their offspring's sleep. ${ }^{13,14}$

According to developmental origins of health and disease theory, environmental exposure during pregnancy could affect the development and programming of the embryo. ${ }^{15,16}$ It has been proposed that an individual's circadian rhythm begins in the embryo. ${ }^{17,18}$ Melatonin, a circadian rhythm messenger linking mother and fetus, has essential functions not only in fetal maturation but also in children's sleep patterns. ${ }^{18-24}$ Because it has been confirmed that sleep disturbance during pregnancy could interfere with the rhythm and amplitude of melatonin secretion, ${ }^{16,25}$ we strongly hypothesized that maternal sleep was associated with their offspring's sleep. Two animal studies provided evidence for our hypothesis. ${ }^{26,27}$ They found that if female rats experienced sleep restriction in the third trimester, their pups had higher active sleep and lower quiet sleep as well as wakefulness. ${ }^{26}$ More impressively, if sleep deprivation took place in the rapid eye movement sleep phase at the third trimester, the development and maturation of their pups' sleep-wake neural networks would be delayed. ${ }^{27}$ To the best of our knowledge, the relationship of maternal sleep with childhood sleep in humans has been discussed in only two studies since $1998 .^{28,29}$ The first was a retrospective case-control study in 97 mother-child dyads, in which it was found that those mothers experienced a higher level of maternal sleep distress when their children had sleep problems. ${ }^{28}$ The other study, based on a prospective cohort containing 111 mother-child dyads, found that maternal exposure to daytime sleepiness could predict childhood sleep problems. ${ }^{29}$

Based on the previous studies, we explored two questions: (1) if there were associations between maternal sleep duration during pregnancy and childhood sleep duration and sleep disturbance; and (2) if the strength of the association of sleep duration with childhood sleep duration and sleep disturbance were different between different trimesters.

\section{Materials and Methods}

\section{Study Design and Participants}

This study was based on a cross-sectional study conducted in 31 preschools in Shanghai, China during May, 2019.
The institutional review board of the Shanghai Municipal Education Commission approved this study.

After the permissions were obtained from these schools, children who were eligible to participate in this study were invited to bring a questionnaire to their parents, with a letter explaining the objectives of the project and instructions on how to complete the questionnaire. Parents were told that participation was voluntary and written informed consent should be signed to confirm. Among 6389 children recruited to the study, 6236 (response rate $97.62 \%$ ) returned the qualified questionnaires. Our final sample consisted of 6236 mother-child dyads with children aged 3-7 years.

Children with any of the following conditions were excluded from the study: (1) death of the mother; (2) parents were illiterate; (3) inability to locate the parents to complete the questionnaire; (4) children take certain drugs (such as aspirin, Ritalin, amphetamine, caffeine, diazepam, phenobarbital, etc.) for a long time or recently (within one week).

\section{Measures}

\section{Demographic Characteristics}

All the demographic characteristics were reported through the questionnaire by mothers. Maternal characteristics were listed as follows: maternal age at delivery was grouped into $<25,25-34$, and $\geq 35$ years; maternal educational level was categorized into less than high school, high school, and college and above; family structure was grouped into singleparent family, nuclear family, and large family; overweight/ obesity before pregnancy was defined as body mass index (BMI) $>24.0 \mathrm{~kg} / \mathrm{m}^{2}$ (yes vs no) according to modified the standard by group of China obesity; ${ }^{30}$ family income (RMB (yuan)/month/person) was categorized into <3999, 4000-7999, and $>8000$; smoking during pregnancy (yes vs no); alcohol use during pregnancy (yes vs no); maternal physical activity was categorized into $<2 \mathrm{~h} /$ day vs $\geq 2 \mathrm{~h} /$ day; maternal stressful life event (including financial problems, divorce, husband violence, lost job, illness/injury of someone close, death of someone close, relationship difficulties, accident/natural disaster) exposure (yes vs no); family history of sleep disorders (yes vs no). Childhood characteristics included age, gender, obesity/overweight (calculated by age and sex-specific BMI reference ${ }^{31}$ ); allergic disease (including allergic rhinitis, eczema, and asthma); attention deficit hyperactivity disorder (ADHD) (yes vs no); childhood physical activity was categorized into $\geq 1 \mathrm{~h} /$ day vs $<1 \mathrm{~h} /$ day according to previous study; ${ }^{32}$ and screen exposure 
was categorized into $\geq 1 \mathrm{~h} /$ day vs $<1 \mathrm{~h} /$ day according to previous study. ${ }^{33}$

\section{Sleep Duration and Sleep Disturbance}

Maternal sleep duration around pregnancy was retrospectively collected through a set of questions at the time of the child sleep assessment, including: "How long did you actually sleep per day on average during the first trimester?' "How long did you actually sleep per day on average during the second trimester?" "How long did you actually sleep per day on average during the third trimester?" Short sleep duration was defined as less than $8 \mathrm{~h} / \mathrm{night}$ as recommended by the American Academy of Sleep Medicine. ${ }^{34}$

The Children's Sleep Habits Questionnaire (CSHQ) $)^{35}$ was used to assess children's sleep habits and sleep problems and sleep duration. CSHQ was a 36-item parentreported questionnaire, which was designed and developed to assess sleep behaviors of preschool and school-aged children. ${ }^{35}$ Respondents were asked to indicate how often the sleep behaviors occurred over a "typical" recent week using a three-point scale: "usually" if it occurred 5-7 times per week, "sometimes" for 2-4 times per week, and "rarely" for $0-1$ time per week. The 33 sleep problems were conceptually grouped into eight subscales: bedtime resistance, sleep onset delay, sleep duration disorder, sleep anxiety, night awakening, parasomnias, sleep-disordered breathing, and daytime sleepiness. In the CSHQ, sleep duration was examined by the question: "What time does your child actually sleep during weekdays and on weekends (including daytime nap)?" In our study, childhood sleep duration was the average of sleep duration during weekdays and on weekends (calculated as: childhood sleep duration $=5 / 7 \times$ Sleep duration during weekdays $+2 / 7 \times$ Sleep duration on weekends). CSHQ score was calculated by the sum of 33 question (higher is worse) ${ }^{35}$ Short sleep duration was defined as less than $10 \mathrm{~h} / \mathrm{night}$ as recommended by the American Academy of Sleep Medicine. ${ }^{34}$ Sleep disturbance was defined as total CSHQ score $>41 .{ }^{35}$

\section{Statistical Analysis}

The description was made by use of the mean and SD (standard deviation) for continuous variables, and number and percentage for categorical variables.

Independent $t$-test and chi-squared test were used to compare differences between two groups. Pearson correlation coefficient was used to analyze the correlation of maternal sleep duration in three trimesters. RM-ANOVA (repeated measurement analysis of variance) was used to compare the differences of maternal sleep duration in three trimesters. Penalized splines in generalized additive models were used to examine the linearity of relationships between maternal sleep duration during pregnancy with childhood sleep duration and childhood CSHQ score. Generalized cross-validation was used to automatically select the degree of smoothing for splines.

Multiple linear regressions were further applied to assess the associations of maternal sleep duration with sleep duration and CSHQ score in offsprings. Logistic regression analyses were then applied to examine the risk of short maternal sleep duration on short sleep duration and sleep disturbance in their offspring. Adjusted models were controlled for maternal age at delivery, maternal education level, overweight/obesity before pregnancy, family structure, family income, smoking during pregnancy, alcohol use during pregnancy, physical activity during pregnancy, maternal stressful life events, family history of sleep disorder, children's age, gender, obesity/ overweight, allergic disease, ADHD, childhood physical activity, and screen exposure.

A statistical significance level was set at $p<0.05$ (twotailed). All analyses were performed with the Statistical Package for the Social Sciences (SPSS) (IBM-SPSS Statistics v24.0, Inc., Chicago, IL) and R version 3.5.3 (The R Foundation for Statistical Computer, www.r-project.org).

\section{Results}

\section{Sample Demographic Characteristics}

A total of 6236 children were enrolled in this study. Among the 6236 children, 2150 children $(34.5 \%)$ reported short sleep duration and 5874 children (94.19\%) reported sleep disturbance. Sample characteristics are shown in Table 1.

\section{Comparisons of Maternal Sleep Duration with Childhood Sleep Duration and Sleep Disturbance}

As shown in Table 2, maternal sleep duration among three trimesters was correlated and showed a slightly deceased trend through the first trimester to the third trimester. Correspondingly, the prevalence of short sleep duration increased with the progress of the pregnancy. As shown in Table 3, children with short sleep duration reported less maternal sleep duration and higher prevalence of insufficient maternal sleep duration in all three trimesters (all $p<0.05$ ). Similarly, children with sleep disturbance also showed the trend in all three trimesters. 


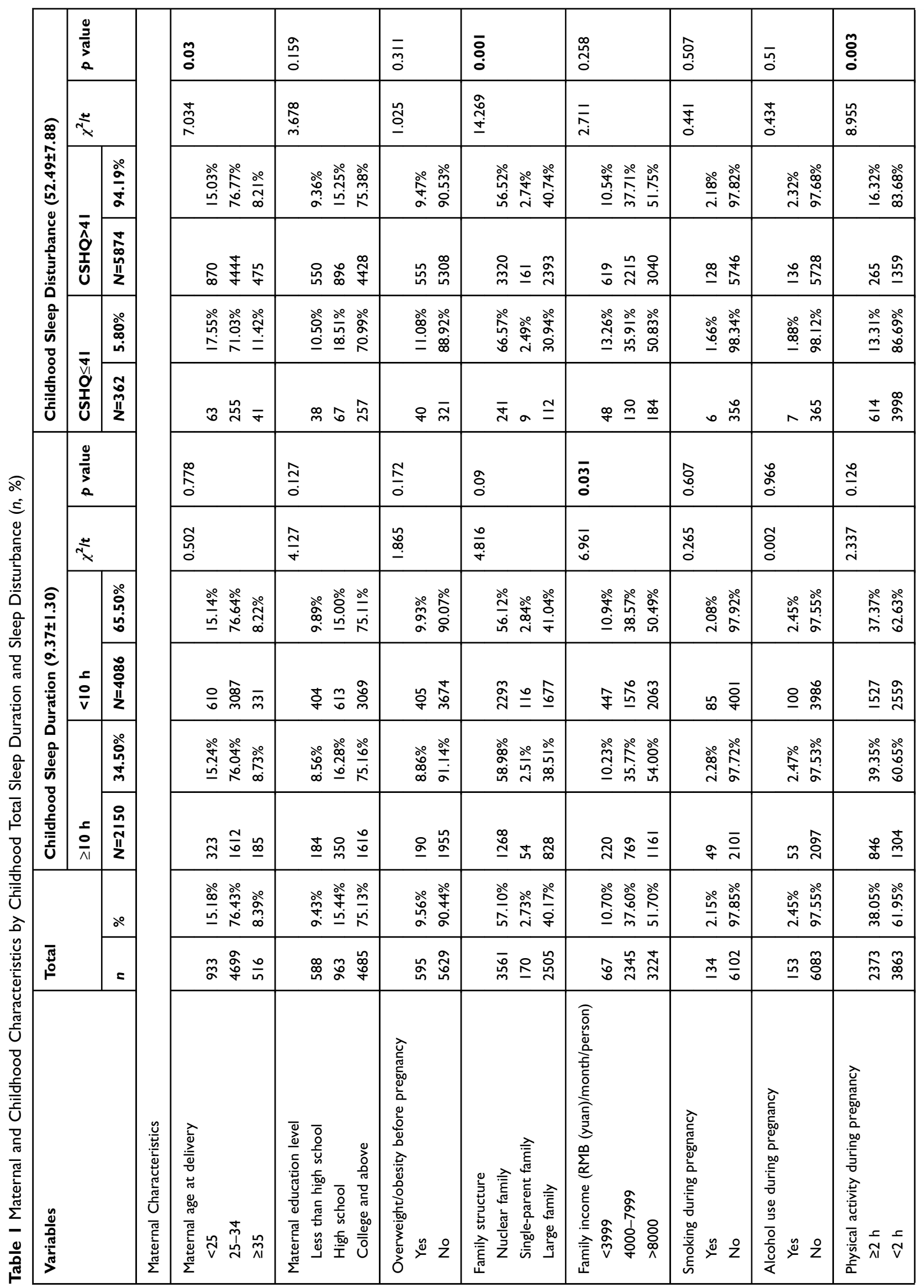




\begin{tabular}{|c|c|c|c|c|c|c|c|c|}
\hline$\frac{y_{0}^{\frac{1}{3}}}{0}$ & ō & $\mid$ & 产 & $\frac{\alpha}{\partial}$ & 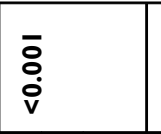 & $:$ & $\mid \begin{array}{l}\bar{o} \\
\dot{i} \\
\end{array}$ & పี \\
\hline 咅 & 蒿 & \begin{tabular}{|l|}
$\bar{a}$ \\
$\vec{p}$ \\
\end{tabular} & 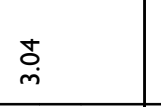 & 晜 & 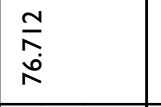 & 总 & 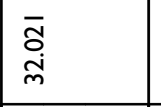 & $\frac{\alpha}{\partial \alpha}$ \\
\hline 象 & 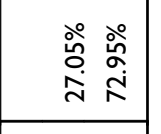 & \begin{tabular}{|l|l}
$\infty$ \\
$\infty$ \\
0
\end{tabular} & 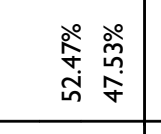 & 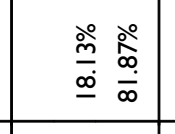 & 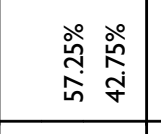 & 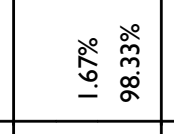 & 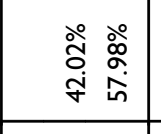 & 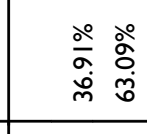 \\
\hline$\underline{n}$ & 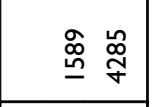 & $\frac{ \pm}{\omega i}$ & 弯 & 兽 & 总言 & 赵 & 孚号号 & $\frac{\infty}{\sim}$ \\
\hline | & | & 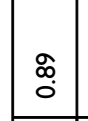 & | & 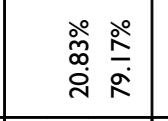 & 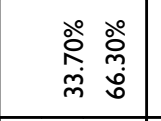 & | & 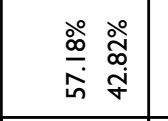 & 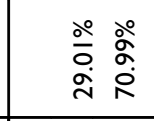 \\
\hline$\underline{\underline{g}}$ & 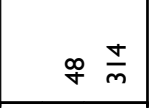 & 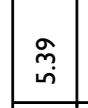 & 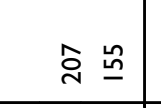 & م: & $\approx \stackrel{q}{d}$ & $-\bar{s}$ & 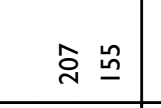 & $\underline{\underline{0}}$ \\
\hline$\Xi$ & 愛 & \begin{tabular}{|l|} 
\\
$\bar{o}$ \\
\end{tabular} & 总 & 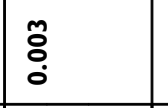 & : & $\bar{\alpha}$ & ō & $\frac{\bar{\partial}}{\partial}$ \\
\hline 唇 & 高 & 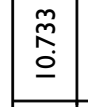 & 怘 & \begin{tabular}{|}
$\mathscr{\infty}$ \\
$\infty$ \\
$\infty$
\end{tabular} & $\frac{\pi}{0}$ & \begin{tabular}{|l}
$\frac{\infty}{0}$ \\
0
\end{tabular} & 惫 & 金 \\
\hline 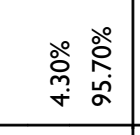 & 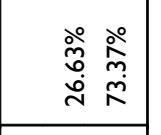 & \begin{tabular}{|l|l}
$\mathbf{a}$ \\
\\
\end{tabular} & 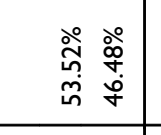 & 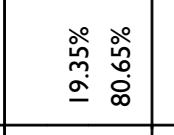 & 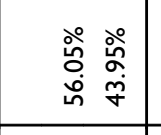 & 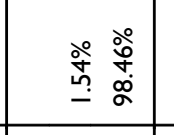 & 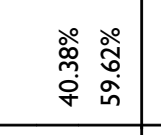 & 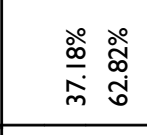 \\
\hline$\stackrel{2}{\cong}$ & 总总 & 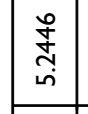 & 产兽离 & 容 $\overline{\tilde{g}}$ & 荨 & : & 总总 & 爰总 \\
\hline 然高 & 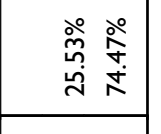 & \begin{tabular}{|l|l|}
\multirow{2}{*}{} \\
\end{tabular} & 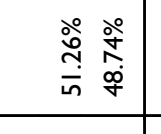 & 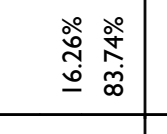 & 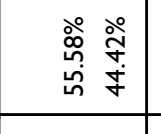 & 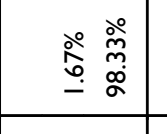 & 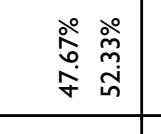 & 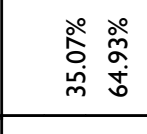 \\
\hline$\therefore \stackrel{\circ}{\circ}$ & 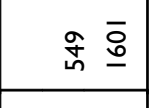 & 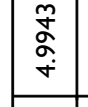 & 을 & 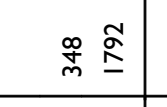 & 哭吕 & 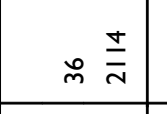 & 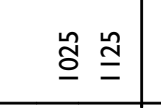 & 志点 \\
\hline 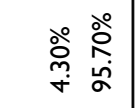 & 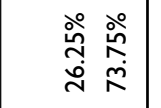 & \begin{tabular}{|l|}
$\mathbf{m}$ \\
$\mathbf{0}$
\end{tabular} & | & 资 & 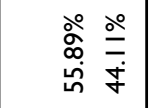 & 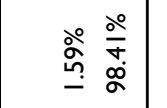 & 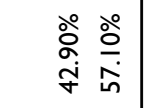 & 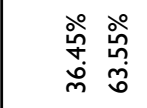 \\
\hline 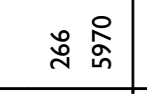 & $\underline{\underline{z}}$ & $\frac{\circ}{\frac{\pi}{\omega}}$ & 啹高 & 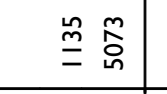 & 总副 & $2 \frac{\hat{0}}{0}$ & 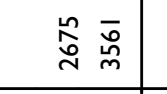 & 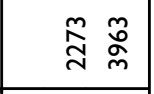 \\
\hline$\because z$ & 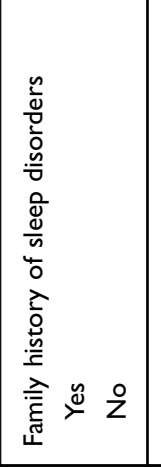 & & ن & 20 & 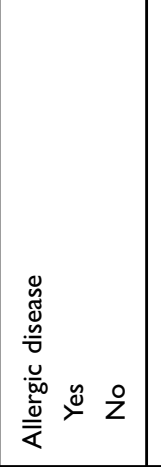 & 虽急足 & & 总 \\
\hline
\end{tabular}


Table 2 Correlation and Longitude Analysis of Maternal Sleep Duration in Three Trimesters

\begin{tabular}{|c|c|c|}
\hline \multicolumn{3}{|c|}{$\begin{array}{l}\text { Correlation and Longitudinal Differences of Maternal Sleep } \\
\text { Duration During Pregnancy }\end{array}$} \\
\hline $\begin{array}{l}\text { Correlation coefficient } \\
\text { First trimester vs Second trimester } \\
\text { Second trimester vs Third trimester } \\
\text { First trimester vs Third trimester }\end{array}$ & $\begin{array}{l}0.727 \\
0.713 \\
0.572\end{array}$ & $\begin{array}{l}p \text { value } \\
<0.001 \\
<0.001 \\
<0.001\end{array}$ \\
\hline $\begin{array}{l}\text { RM-ANOVA (Mean Difference) } \\
\text { First trimester vs Second trimester } \\
\text { Second trimester vs Third trimester } \\
\text { First trimester vs Third trimester }\end{array}$ & $\begin{array}{l}0.038 \\
0.351 \\
0.389\end{array}$ & $\begin{array}{l}0.006 \\
<0.001 \\
<0.001\end{array}$ \\
\hline
\end{tabular}

Note: Bold values indicate statistical significance.

Abbreviation: RM-ANOVA, repeated measurement analysis of variance.

\section{Association of Maternal Sleep Duration with Childhood Sleep Duration and Sleep Disturbance}

As shown in generalized additive models by using a penalized spline of maternal sleep duration, a linear association between maternal sleep duration with childhood sleep duration was observed (Figure 1). Similarly, a linear association of maternal sleep duration with childhood CSHQ score were also observed (Figure 2).

Less maternal sleep duration was observed in all three trimesters when their children had either shorter sleep duration $(\beta=0.113, \quad \beta=0.131$, and $\beta=0.088$ for the first, second, and third trimesters, respectively, all $p<0.01)$ or sleep disturbance $(\beta=-0.308, \beta=-0.392$, and $\beta=-0.300$ for the first, second, and third trimesters, respectively, all $p<0.01)$. After controlling for possible confounders, the associations were still kept (Tables 3 and 4).

Correspondingly, maternal short sleep duration, no matter in which trimester, could predict both short sleep duration $(\mathrm{OR}=1.24, \mathrm{OR}=0.133$, and $\mathrm{OR}=1.30$ for the first, second, and third trimesters, respectively, all $p<0.01)$ and sleep disturbance $(\mathrm{OR}=1.28, \mathrm{OR}=1.41$, and $\mathrm{OR}=1.34$ for the first, second, and third trimesters, respectively, all $p<0.01$ ) in their children. After controlling for possible confounders, the associations were also kept, especially in the second and third trimesters (Tables 3 and 5).

Based on these results in linear and logistic regressions, the associations between maternal sleep duration and childhood sleep duration and childhood sleep disturbance have been preliminarily established, especially in the second and the third trimesters.

\section{Discussion}

To our knowledge, only a few studies have indicated that maternal sleep could be involved in the offspring's childhood sleep characteristics. ${ }^{26-29}$ Our study provides more detailed sleep parameters from humans on the basis of a population-based epidemiological study. It is also worth noting that maternal sleep from middle to late gestation, especially in the second trimester, was more important to their children's sleep pattern. The findings enriched our understanding with sleep health and the origins of childhood sleep pattern.

In the present study, we applied data analysis taking sleep duration and sleep disturbance not only as continuous variables but also cutting them into categorical variables. The very similar results confirmed the findings and enforced the evidence. In addition, demographic characteristics and a number of lifestyle factors were taken into account when examining the associations. Also, as suggested by previous studies, maternal mood during pregnancy was a predictor of childhood sleep quality and sleep disorders. ${ }^{13,14}$ In this study, we used maternal exposure to stressful life events as an indicator of mood and stress ${ }^{36}$ and took it as a confounding factor when discussing the association of maternal sleep with childhood sleep. Therefore, maternal sleep could be independently related to childhood sleep pattern.

Genetic imprinting between mother and offspring in their behavioral connections have been confirmed by accumulating animal studies. ${ }^{26,27,37}$ At least two studies in rats found sleep restriction and sleep duration during pregnancy have negative impact on offspring's sleep-wake network development. ${ }^{26,27}$ In addition, two studies provided evidence to support the relationship between maternal sleep and childhood sleep in humans. ${ }^{28,29}$ The data from a retrospective case-control study found that sleep problems during pregnancy were more prevalent among those mothers when their children were exposed to poor sleep quality compared to the control. ${ }^{28}$ A longitudinal study also found that maternal daytime sleepiness during pregnancy could predict childhood sleep problems. ${ }^{29}$ Our study further provided enriched information to discuss the association between maternal sleep and childhood sleep based on a large-sample epidemiology study.

Our finding also extended the understanding that there should be a key period for the development of sleep patterns. Our results suggested that middle to late gestation may be more crucial for offspring's sleep pattern. 


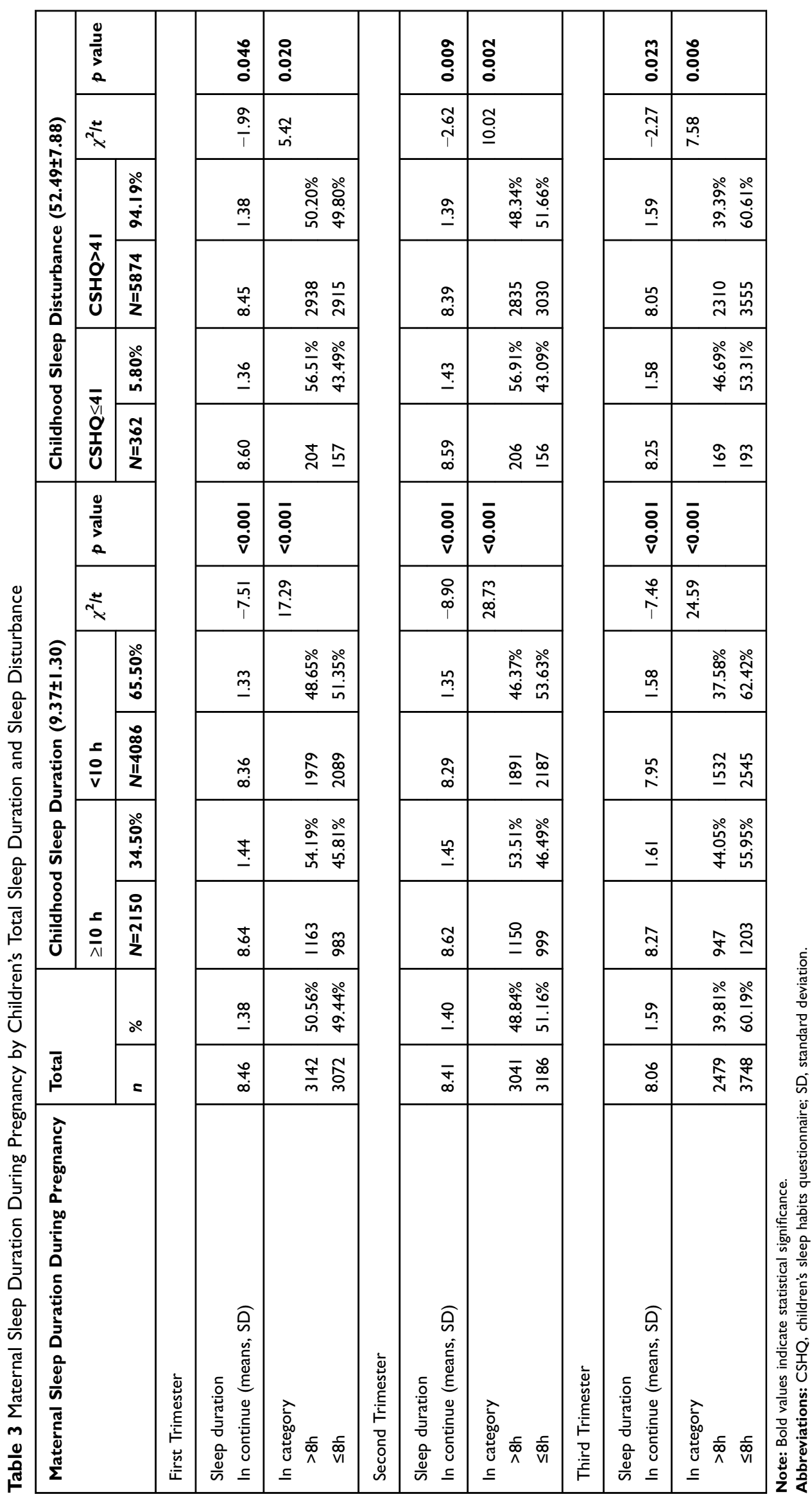



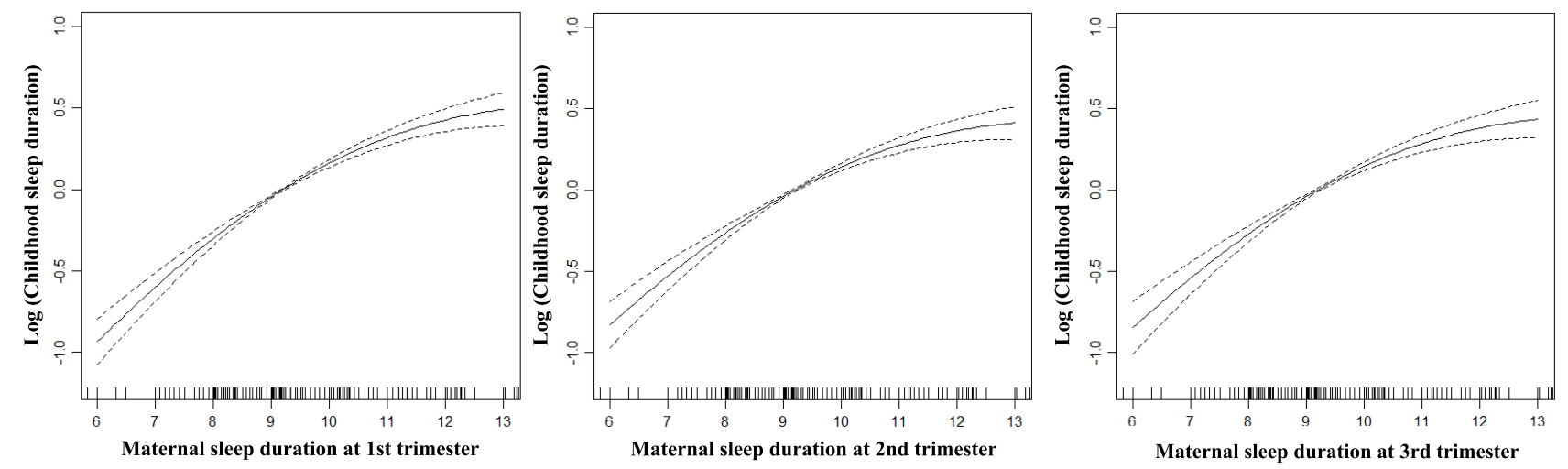

Figure I The associations between maternal sleep duration during pregnancy with childhood sleep duration.
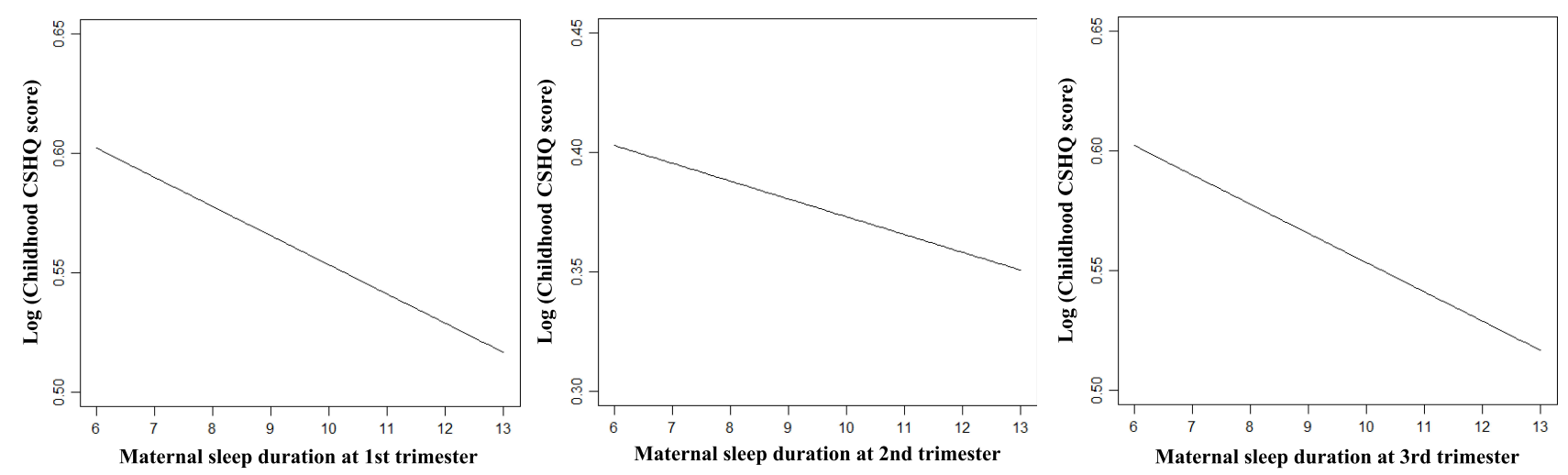

Figure 2 The associations between maternal sleep duration during pregnancy with childhood CSHQ score.

Compared with the first trimester, the impact of maternal sleep became stronger in the second and third trimesters. As demonstrated by previous studies, fetal circadian rhythms were developed in the second trimester and matured in the third trimester. ${ }^{17,38}$ We speculate that the second trimester could be a "window period" for the establishment of sleep patterns in the fetus due to the start of circadian rhythms. It has been reported that circadian rhythms became mature and could be influenced by the outside environment, such as light. ${ }^{23}$ The fetus has the ability to sense changes in the maternal sleep-wake cycle during the third trimester. ${ }^{23}$

Although few studies discussed the relationship between maternal sleep and childhood sleep, some potential biological mechanisms have been proposed in theory to support the relationship. Previous studies have put forward an explanation that disturbed sleep during pregnancy could interfere with the rhythm and amplitude of melatonin secretion. ${ }^{16,25}$ Melatonin plays a role of circadian rhythm messenger between mother and fetus, which should be involved in the form of normal fetal sleep patterns and circadian rhythms. ${ }^{18,19}$ We speculated that the melatonin regulated the circadian rhythms and brought about the associations between maternal sleep and childhood sleep. There has been evidence to support the association of maternal melatonin with children's sleep by longitudinal observation. ${ }^{22}$

The biggest strength of our study was the big sample size to explore the relationship between maternal sleep and childhood sleep pattern in population. Second, maternal sleep covered three trimesters. Third, our study was conducted with a large sample. Other strengths included the proper questionnaire (CSHQ) and confounding factor controls.

However, there were also some limitations in interpreting the data. Based on a retrospective cross-sectional study, recall bias of maternal sleep duration cannot be ignored. However, as a special period, mothers always pay close attention to their health during pregnancy, so recall bias may be limited to a certain extent. Meanwhile, in data analysis, sleep duration and sleep disturbance were brought into the regression model as 
Table 4 Associations of Maternal Sleep Duration During Pregnancy with Childhood Sleep Duration and CSHQ Score in Their Offsprings

\begin{tabular}{|c|c|c|c|c|c|c|}
\hline \multirow[t]{2}{*}{ Maternal Sleep Duration } & \multicolumn{3}{|c|}{ Childhood Sleep Duration $(9.37 \pm 1.30)$} & \multicolumn{3}{|c|}{ Childhood CSHQ Score $(52.49 \pm 7.88)$} \\
\hline & $\boldsymbol{\beta}$ & SE & $p$ value & $\beta$ & SE & $p$ value \\
\hline $\begin{array}{l}\text { First Trimester } \\
\text { Sleep duration }\end{array}$ & 0.113 & 0.012 & $<0.001$ & -0.308 & 0.072 & $<0.001$ \\
\hline $\begin{array}{l}\text { Second Trimester } \\
\text { Sleep duration }\end{array}$ & 0.131 & 0.012 & $<0.001$ & -0.392 & $0.07 I$ & $<0.001$ \\
\hline $\begin{array}{l}\text { Third Trimester } \\
\text { Sleep duration }\end{array}$ & 0.088 & 0.10 & $<0.001$ & -0.300 & 0.061 & $<0.001$ \\
\hline
\end{tabular}

Notes: Bold values indicate statistical significance. Adjusted for maternal age at delivery, maternal education level, overweight/obesity before pregnancy, family structure, family income, smoking during pregnancy, alcohol use during pregnancy, physical activity during pregnancy, maternal stressful life events, family history of sleep disorder, children's age, gender, obesity/overweight, allergic disease, ADHD, childhood physical activity, and screen exposure.

Abbreviations: CSHQ, children's sleep habits questionnaire; SE, standard error.

Table 5 The Association of Maternal Short Sleep Duration with Childhood Short Sleep Duration and Sleep Disturbance in Their Offsprings

\begin{tabular}{|c|c|c|c|c|}
\hline \multirow[t]{2}{*}{ Maternal Sleep Duration } & \multicolumn{2}{|c|}{ Childhood Short Sleep Duration (Less Than 10 h/day) } & \multicolumn{2}{|c|}{ Childhood Sleep Disturbance (CSHQ $>4 I^{*}$ ) } \\
\hline & Crude OR $(95 \% \mathrm{CI})$ & Adjusted OR (95\% Cl) & Crude OR $(95 \% \mathrm{Cl})$ & Adjusted OR (95\% Cl) \\
\hline \multicolumn{5}{|l|}{ First Trimester } \\
\hline \multicolumn{5}{|l|}{ Sleep duration } \\
\hline$>8 \mathrm{~h}$ & Reference & Reference & Reference & Reference \\
\hline$\leq 8 \mathrm{~h}$ & $1.24(1.12,1.38)^{\#}$ & $1.25(1.12,1.39)^{\#}$ & $1.28(1.04,1.59)^{\#}$ & $1.13(0.90,1.42)$ \\
\hline \multicolumn{5}{|l|}{ Second Trimester } \\
\hline \multicolumn{5}{|l|}{ Sleep duration } \\
\hline$>8 \mathrm{~h}$ & Reference & Reference & Reference & Reference \\
\hline$\leq 8 \mathrm{~h}$ & $1.33(1.199,1.47)^{\#}$ & $1.33(1.19,1.49)^{\#}$ & $1.41(1.13,1.74)^{\#}$ & $1.28(1.02,1.54)^{*}$ \\
\hline \multicolumn{5}{|l|}{ Third Trimester } \\
\hline \multicolumn{5}{|l|}{ Sleep duration } \\
\hline$>8 \mathrm{~h}$ & Reference & Reference & Reference & Reference \\
\hline$\leq 8 \mathrm{~h}$ & $1.30(1.17,1.45)^{\#}$ & $1.33(1.19,1.48)^{\#}$ & $1.34(1.08,1.66)^{\#}$ & $1.26(1.01,1.45)^{*}$ \\
\hline
\end{tabular}

Notes: Bold values indicate statistical significance. Adjusted for maternal age at delivery, maternal education level, overweight/obesity before pregnancy, family structure, family income, smoking during pregnancy, alcohol use during pregnancy, physical activity during pregnancy, maternal stressful life events, family history of sleep disorder, children's age, gender, obesity/overweight, allergic disease, ADHD, childhood physical activity, and screen exposure. ${ }^{*} p<0.05 ;{ }^{*} p<0.01$.

Abbreviations: CSHQ, children's sleep habits questionnaire; Cl, coefficient interval; OR, odds ratio.

continuous variables or cutting them into categorical variables, respectively. The very similar results could enforce the evidence. This study did not collect maternal sleep at the time of child sleep assessment, however, which should be taken into account when exploring the relationship of maternal sleep during pregnancy with childhood sleep. Children's sleep was reported by their parents rather than objective recording. This made it possible that there are biases in children's sleep variables because of reporting bias. We made a preliminary research on maternal sleep during pregnancy and childhood sleep; other maternal sleep parameters, such as sleep problems and sleep disturbance, were unavailable in the present study.

\section{Conclusion}

This study, for the first time, established the associations of maternal sleep duration through the whole pregnancy with childhood sleep duration and sleep disturbance. However, middle to late gestation was more important to the associations. Insufficient maternal sleep duration was associated with childhood short sleep duration and sleep disturbance. The findings provided new evidence to 
support the relationship between maternal sleep during pregnancy and childhood sleep, which has been discussed by only two studies so far. ${ }^{28,29}$ Due to the retrospective design of our study, prospective longitudinal studies are needed to provide further and enriched evidence.

\section{Acknowledgment}

The study was funded by special grant for Preschool Children's Health Management from Shanghai Municipal Education Commission, grants from National Natural Science Foundation of China (81874266, 81673183), and Key Project from Shanghai Municipal Science and Technology Commission (18411951600).

\section{Disclosure}

The authors report no conflicts of interest in this work.

\section{References}

1. Mindell JA, Owens J, Alves R, et al. Give children and adolescents the gift of a good night's sleep: a call to action. Sleep Med. 2011;12 (3):203-204. doi:10.1016/j.sleep.2011.01.003

2. Reynaud E, Vecchierini M-F, Heude B, Charles M-A, Plancoulaine S. Sleep and its relation to cognition and behaviour in preschool-aged children of the general population: a systematic review. J Sleep Res. 2018;27(3):e12636. doi:10.1111/jsr.2018.27.issue-3

3. Simon SL, Goetz AR, Meier M, Brinton J, Zion C, Stark LJ. Sleep duration and bedtime in preschool-age children with obesity: relation to BMI and diet following a weight management intervention. Pediatr Obes. 2019;14(11):e12555. doi:10.1111/ijpo.v14.11

4. Tomaz SA, Prioreschi A, Watson ED, et al. Body mass index, physical activity, sedentary behavior, sleep, and gross motor skill proficiency in preschool children from a low- to middle-income urban setting. $J$ Phys Act Health. 2019;16(7):525-532. doi:10.1123/ jpah.2018-0133

5. Van Dyk TR, Becker SP, Byars KC. Mental health diagnoses and symptoms in preschool and school age youth presenting to insomnia evaluation: prevalence and associations with sleep disruption. Behav Sleep Med. 2019;17(6):790-803. doi:10.1080/15402002.2018.1518 224

6. Lin J, Magiati I, Chiong SHR, et al. The relationship among screen use, sleep, and emotional/behavioral difficulties in preschool children with neurodevelopmental disorders. J Dev Behav Pediatr. 2019;40 (7):519-529. doi:10.1097/DBP.0000000000000683

7. Sampei M, Dakeishi M, Wood DC, Murata K. Impact of total sleep duration on blood pressure in preschool children. Biomed Res. 2006;27(3):111-115. doi:10.2220/biomedres.27.111

8. Bordeleau S, Bernier A, Carrier J. Longitudinal associations between the quality of parent-child interactions and children's sleep at preschool age. J Fam Psychol. 2012;26(2):254-262. doi:10.1037/ a0027366

9. Jafar NK, Tham EKH, Eng DZH, et al. The association between chronotype and sleep problems in preschool children. Sleep Med. 2017;30:240-244. doi:10.1016/j.sleep.2016.11.015

10. Ostrzyzek-Przezdziecka K, Smeding C, Bronikowski M, Panczyk M, Feleszko W. The association of physical activity and sedentary behaviors with upper respiratory tract infections and sleep duration in preschool children-study protocol. Int J Environ Res Public Health. 2019;16(9):1496. doi:10.3390/ijerph16091496
11. Wada K, Nakamura K, Tamai Y, et al. Associations of endogenous melatonin and sleep-related factors with behavioral problems in preschool Japanese children. Ann Epidemiol. 2013;23(8):469-474. doi:10.1016/j.annepidem.2013.05.013

12. Santos IS, Mota DM, Matijasevich A. Epidemiology of co-sleeping and nighttime waking at 12 months in a birth cohort. $J$ Pediatr (Rio J). 2008;84(2):114-122. doi:10.2223/JPED.1766

13. O’Connor TG, Caprariello P, Blackmore ER, et al. Prenatal mood disturbance predicts sleep problems in infancy and toddlerhood. Early Hum Dev. 2007;83(7):451-458. doi:10.1016/j.earlhumdev.20 06.08.006

14. Toffol E, Lahti-Pulkkinen M, Lahti J, et al. Maternal depressive symptoms during and after pregnancy are associated with poorer sleep quantity and quality and sleep disorders in 3.5-year-old offspring. Sleep Med. 2019;56:201-210. doi:10.1016/j.sleep.2018. 10.042

15. Gillman MW, Barker D, Bier D, et al. Meeting report on the 3rd International Congress on Developmental Origins of Health and Disease (DOHaD). Pediatr Res. 2007;61(5 Pt 1):625-629. doi:10. 1203/pdr.0b013e3180459fcd

16. Silveira PP, Portella AK, Goldani MZ, Barbieri MA. Developmental origins of health and disease (DOHaD). J Pediatr (Rio J). 2007;83 (6):494-504. doi:10.2223/JPED.1728

17. Li SF, Wang Y, Li GF, Zhao YY, Chen L, Zhang S. [Diurnal rhythm of fetal heart rate in third trimester of pregnancy]. Zhonghua Fu Chan Ke Za Zhi. 2018;53(12):849-854. Chinese. doi:10.3760/cma.j. issn.0529-567x.2018.12.009

18. Gallaher KGH, Slyepchenko A, Frey BN, Urstad K, Dorheim SK. The role of circadian rhythms in postpartum sleep and mood. Sleep Med Clin. 2018;13(3):359-374. doi:10.1016/j.jsmc.2018.04.006

19. Jin Y, Choi J, Won J, Hong Y. The relationship between autism spectrum disorder and melatonin during fetal development. Molecules. 2018;23(1):198. doi:10.3390/molecules23010198

20. Nishihara K, Horiuchi S, Eto H, Kikuchi S, Hoshi Y. Relationship between infant and mother circadian rest-activity rhythm pre- and postpartum, in comparison to an infant with free-running rhythm. Chronobiol Int. 2012;29(3):363-370. doi:10.3109/07420528.2012.657762

21. Simonneaux V. Naughty melatonin: how mothers tick off their fetus. Endocrinology. 2011;152(5):1734-1738. doi:10.1210/en.2011-0226

22. Diethelm K, Libuda L, Bolzenius K, Griefahn B, Buyken AE, Remer T. Longitudinal associations between endogenous melatonin production and reported sleep duration from childhood to early adulthood. Horm Res Paediatr. 2010;74(6):390-398. doi:10.1159/ 000303134

23. Reiter RJ, Tan DX, Korkmaz A, Rosales-Corral SA. Melatonin and stable circadian rhythms optimize maternal, placental and fetal physiology. Hum Reprod Update. 2014;20(2):293-307. doi:10.1093/ humupd/dmt054

24. Voiculescu SE, Zygouropoulos N, Zahiu CD, Zagrean AM. Role of melatonin in embryo fetal development. $J$ Med Life. 2014;7 (4):488-492.

25. Shimada M, Seki H, Samejima M, Hayase M, Shirai F. Salivary melatonin levels and sleep-wake rhythms in pregnant women with hypertensive and glucose metabolic disorders: a prospective analysis. Biosci Trends. 2016;10(1):34-41. doi:10.5582/bst.2015.01123

26. Aswathy BS, Kumar VM, Gulia KK. Immature sleep pattern in newborn rats when dams encountered sleep restriction during pregnancy. Int J Dev Neurosci. 2018;69:60-67. doi:10.1002/(ISSN) 1873-474X

27. Aswathy BS, Kumar VM, Gulia KK. The effects of rapid eye movement sleep deprivation during late pregnancy on newborns' sleep. J Sleep Res. 2018;27(2):197-205. doi:10.1111/jsr.12564

28. Armstrong KL, O'Donnell H, McCallum R, Dadds M. Childhood sleep problems: association with prenatal factors and maternal distress/depression. J Paediatr Child Health. 1998;34(3):263-266. doi:10.1046/j.1440-1754.1998.00214.x 
29. Lahti-Pulkkinen M, Mina TH, Riha RL, et al. Maternal antenatal daytime sleepiness and child neuropsychiatric and neurocognitive development. Psychol Med. 2019;49(12):2081-2090. doi:10.1017/ S003329171800291X

30. Zhou B. Coorperative Meta-Analysis Group Of China Obesity Task Force. [Predictive values of body mass index and waist circumference to risk factors of related diseases in Chinese adult population]. Zhonghua Liu Xing Bing Xue Za Zhi. 2002;23(1):5-10. Chinese.

31. Ma GS, Li YP, Hu XQ, Cui ZH, Yang XG, Chen CM. Report on childhood obesity in China (2). Verification of BMI classification reference for overweight and obesity in Chinese children and adolescents. Biomed Environ Sci. 2006;19(1):1-7.

32. Quan M, Zhang H, Zhang J, et al. Are preschool children active enough in Shanghai: an accelerometer-based cross-sectional study. BMJ Open. 2019;9(4):e024090. doi:10.1136/bmjopen-2018-024090

33. Zhao J, Zhang Y, Jiang F, et al. Excessive screen time and psychosocial well-being: the mediating role of body mass index, sleep duration, and parent-child interaction. J Pediatr. 2018;202:157-162 e151. doi:10.1016/j.jpeds.2018.06.029
34. Paruthi S, Brooks LJ, D'Ambrosio C, et al. Recommended amount of sleep for pediatric populations: a consensus statement of the american academy of sleep medicine. J Clin Sleep Med. 2016;12(6):785-786. doi: $10.5664 /$ jesm.5866

35. Owens JA, Spirito A, McGuinn M. The Children's Sleep Habits Questionnaire (CSHQ): psychometric properties of a survey instrument for school-aged children. Sleep. 2000;23(8):1043-1051. doi:10. 1093/sleep/23.8.1d

36. Lyu J, Zhao K, Xia Y, et al. Associations between maternal social support and stressful life event with ventricular septal defect in offspring: a case-control study. BMC Pregnancy Childbirth. 2019;19 (1):429. doi:10.1186/s12884-019-2541-y

37. Eclarinal JD, Zhu S, Baker MS, et al. Maternal exercise during pregnancy promotes physical activity in adult offspring. FASEB J. 2016;30(7):2541-2548. doi:10.1096/fj.201500018R

38. Seron-Ferre M, Valenzuela GJ, Torres-Farfan C. Circadian clocks during embryonic and fetal development. Birth Defects Res C Embryo Today. 2007;81(3):204-214. doi:10.1002/(ISSN)15429768

\section{Publish your work in this journal}

Nature and Science of Sleep is an international, peer-reviewed, open access journal covering all aspects of sleep science and sleep medicine, including the neurophysiology and functions of sleep, the genetics of sleep, sleep and society, biological rhythms, dreaming, sleep disorders and therapy, and strategies to optimize healthy sleep.
The manuscript management system is completely online and includes a very quick and fair peer-review system, which is all easy to use. Visit http://www.dovepress.com/testimonials.php to read real quotes from published authors. 